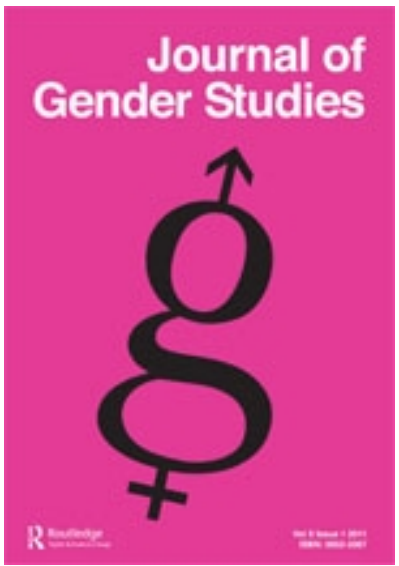

\title{
Men's health across the life course: A gender relational (critical) overview
}

\begin{tabular}{|r|l|}
\hline Journal: & Journal of Gender Studies \\
\hline Manuscript ID & CJGS-2019-0144.R1 \\
\hline Manuscript Type: & Research Articles \\
\hline Keywords: & gender, masculinities, men's health, public health \\
\hline \multicolumn{2}{|l}{} \\
\end{tabular}

\section{SCHOLARONE Manuscripts}




\title{
Men's health across the life course: A gender relational (critical) overview
}

\begin{abstract}
The advances made in incorporating a gender approach into public health policies have stimulated growing interest in the social mechanisms of the study of men's health. Therefore, a more experiential, gender-based analysis that allows for a better understanding of how ill-health processes and exposure to risk factors are related is required. In this paper, based on a rapid review, we focus on the daily circumstances, critical events and social practices in which masculinities become (re)defined during different stages of the life cycle. Our results highlight the dynamics between workplace and family contexts, calling attention to the impact of the male breadwinner model, which acts as a gendered social structure with implications for other factors (including age, social class, disability and marital status) that characterize the dynamics of life-cycle transitions and the key vulnerabilities that transcend occupational health. These findings lead us to consider the possibility that ill-health processes in males and females are intrinsically interwoven, such that the development of relationships reflects limitations and opportunities for both. Our analysis provides greater insights into explanations for gendered patterning in morbidity and mortality as well as how a gender order instigates social vulnerabilities and inequalities in health.
\end{abstract}

Keywords: gender; men's health; masculinities; life cycle stages; public health

\section{Introduction}

Research on men and masculinities is a relatively recent field of study from the perspective of gender in health. Its emergence can be positioned as part of the feminist critique of the functionalist paradigm by limiting the gender approach to the analysis of individual personality traits (Lorber, 1994). In this way, the literature has started to refer to masculinities as configurations of collective practices (Connell, 1987). Additionally emerging from this analysis is the concept of hegemonic masculinity as an analytical instrument to recognize practices and attitudes among men that perpetuate gender inequalities, involving both men's domination over women and the power of some men 
over other (often minority groups of) men (Jewkes et al., 2015). Therefore, the notion of hegemony refers to the dynamic by which men maintain a position of power in public and private spheres. However, this also highlights how interactions between masculinities are complex, underscoring the fact that the experience of being a man is not uniform. Consequently, hegemonic masculinity must be defined as a process, rather than merely as a set of attributive traits (Jefferson, 2002).

This perspective has favoured the (often contradictory) understanding of experiences of being a man, in addition to the challenges inscribed in stereotypes and social expectations associated with being a man in specific contexts. As a result, the hegemonic masculinity concept is increasingly understood as a problem for both women and men in terms of well-being as well as a fundamental cause of inequalities in health. This involves the existence of a dominant construction of masculinity as a promoter of unhealthy practices, characterized by an assessment of attitudes of resistance, aggressiveness, risk adoption or 'emotional illiteracy' (de Visser, 2009). Consequently, it is essential to recognize the interaction of sociocultural factors with gender, both in the construction of identities and in the assignment of roles and responsibilities, as reflected in the health status of men and women (Sabo, 2005).

Attention to why men perform acts that put their health at greater risk has been reinvigorated by the framework provided by Will Courtenay (2000). This author's work has demonstrated that men who share traditional beliefs about manhood are more likely to adopt unhealthy lifestyles. His thesis indicates that not only are some risk behaviours culturally defined as 'masculine', but that men can use them as a means of defining their manhood. In this way, adherence to certain ideals of masculinity contributes to some of the most important differences identified in health between women and men (Evans et al., 2011). Therefore, it is only from a gender perspective that we can 
understand that the higher mortality or accident rate among men and their lower use of preventive health services are connected to conceptions and behaviours associated with the way in which they construct and represent themselves as dominant (Courtenay, 2003).

Health studies have tended to explain differences in men's health based on a behavioural approach, with analysis primarily focusing on the consequences of particular lifestyles. Thus, based on risks, interpretations of health-disease patterns have often been associated with individual decisions and hence with issues of self-control and personal responsibility (Solar et al., 2009). From this point of view, the analysis of risk factors tends to minimize the gender impact of socioeconomic and political structures. This is progressively leading to the study of men and masculinities being framed within a wider range of social factors that help to determine health (White et al., 2011a). Moreover, attention to the ways in which gender is related to equity has progressively brought the concept of masculinity into the ongoing debate regarding the social determinants of health (SDH). Factors pertaining to social support, academic performance and employability conditions (among others) have been shown to influence men's engagement with health services or health promotion campaigns (Robertson, 2008; White et al., 2018). We can note aspects rooted in the development of different types of masculinity according to the ways in which men establish their relationships and direct their performances. This invites us to think about the interrelationship between gendered practices and institutionalized practices. An example lies in the importance given to work and the public sphere as a space for personal fulfilment. In this sense, the gender division of labour has played and continues to play a determining role (Sen \& Östlin, 2007). Thus, despite the advances made during the last few decades in economically developed societies, men still hold a position of 
advantage (Malmusi et al., 2014). However, from a gender perspective, we are not only dealing with issues of a purely economic nature, but also with factors related to power and decision-making capacity. In the specific case of men, this implies that the risks and health problems they face as a result of efforts to meet expectations of their social role must be highlighted (Sabo, 2005).

The inclusion of men in gender equality issues related to public health policies is a relatively recent development and the debate has helped to define equity in a broader sense, maintaining the emphasis on power relations, not only of men over women, but also of men over other men. This idea supports the use of a relational perspective when analyzing health-illness processes (Broom, 2009) and leads us to a more holistic understanding of the variations and inequalities brought about by these gender issues, alongside the complexities of men's health studies from a gender perspective (Schofield et al., 2000).

The framework of SDH enables us to address men's health without overlooking the health of women. This necessitates recognition of the interaction between societalcultural factors, both in identity construction and in the assignment of roles and responsibilities reflected in the health status of men and women (Phillips, 2011), which are themselves nested within the gender order, understood as a patterned system of ideological and material practices performed within a specific context and through which power relations are made (Pilcher \& Whelehan, 2004). Growing concern for the health-related needs and specific risks related to men goes hand in hand with recognition that they must be involved in health programmes aimed at generating positive changes in the gender order (Smith et al., 2009). The life cycle approach can facilitate a deeper understanding of the cumulative effect of male identities in relation to social practices and life's critical events. Thus, when studying masculinities, we should 
explore how an individual's dominant practices change over time through common life events, thereby providing a better understanding of gender's effects on health (Evans et al., 2011), by understanding the social dynamics in which gender identities are (re)negotiated.

By adopting a life cycle approach it is possible to extend the causal chain of explanations for differences in health and how they relate to material, psychosocial and cultural factors. Similarly, this approach implies that the health status of a certain age not only reflects current conditions but also previous life circumstances and therefore must be taken into account (Kawachi et al., 2002). Thus, the temporary nature of exposure variables and their interrelationships should be considered along with the situations, circumstances and social dynamics of everyday life (Graham, 2002). This paper, which is derived from a consulting project for the World Health Organization-Europe regarding the development of a strategy to improve men's health while promoting gender equality (WHO, 2018), is based on a rapid review of literature published since 2000, when men's health emerged as a prominent concern from a gender perspective. The literature reviewed is stored in two electronic databases (MEDLINE/PubMed and Web of Science) and is complemented by articles found using Google Scholar by cross-checking references and selected papers that were already known by the research team. The review was carried out between December 2017 and February 2018. Keywords included 'men's health', 'masculinities', 'life course approach', 'occupational health', 'male breadwinner model' and their alternative terms. Both MeSH (Medical Subject Headings) terms and free-text terms were used. To be included, a study had to meet the following criteria: 1) constituted a research paper referring to masculinities and men's health; 2) presented relevant outcomes in relation to the impact of the life cycle, male breadwinner model and/or occupational health; 3 ) 
was written in English or Spanish; and 4) was published between 2007 and 2017. We additionally considered theoretical papers pertaining to these topics. References were saved in an EndNote library and reviewed to identify potentially relevant papers. Titles and abstracts were assessed by each researcher to determine whether the papers met the general inclusion criteria, with those satisfying these expectations being saved as potential documents. Additional sources were obtained after screening by crosschecking the references of previously known papers by the research team. The selected documents were then assessed with full-text screening; each researcher worked independently in a research topic and any doubts raised during the process were solved through discussion with a fourth researcher. Following a life course approach, content analysis was performed according to categories related to the three previously established dimensions: risky behaviours, the breadwinner model and occupational health. These facilitated comparisons and the identification of gaps in public health policy and research. Finally, we synthesized the findings into meaningful thematic content following a gender-relational approach as proposed by the Australian sociologist Raewyn Connell's theory of masculinity (Wedgwood, 2009). This implied conceiving health concerns in the context of women's and men's interactions with each other, alongside their positions in a multidimensional structure that simultaneously connects socioeconomic, affective, symbolic and power relations and operates at individual, interpersonal and institutional levels (Connell, 2012). This paper allows us to explore how gender operates throughout the life cycle, identifying practices and critical events through transition periods in life that generate vulnerabilities and potential health threats. Specifically, in this overview, we provide insights into some recurrent and emerging issues in the health research literature that through the analysis of daily situations and practices pertain to how masculinities are (re)defined. Although 
masculinities are extremely context-specific, this analysis facilitates a better understanding of men's health beyond individual traits, identifying some current needs that should continue to be explored in this research field from a gender standpoint.

\section{Young men's health: risks and gender identity}

Gender has considerable relevance when defining expectations and social roles, which from a relational approach can be seen as negotiation processes between people. This implies that through a gender analysis, it is not only possible to capture the parallelism between an individual and identity, but also between identity and risk. The results suggest that in the case of young people, the relationship between masculinity and health has an important performative component. Thus, for some young people, exhibiting certain attitudes and practices that are believed to be associated with hegemonic identities can constitute a challenge in itself.

\section{The effects of masculinity and its health risk behaviours}

This stage in the life cycle is critical when analyzing the role of risk in the development of gender identities (Perry \& Pauletti, 2011). Analysis of the different meanings attributed to the idea of masculinity necessitates attention to socialization processes. This also implies an awareness of the existence of hierarchies of masculinity associated with idealized or dominant versions. In this sense, the results point to aspects embedded in different forms of power representation and/or domination among men. The literature that we reviewed provides examples such as recklessness, road accidents, violent behaviours and the influence of body image.

Road accidents have been increasingly studied from a gender perspective, with statistics showing that young men (Organisation for Economic Co-operation and Development/ International Transport Forum, OECD/ITF, 2018) are subject 
to the greatest risk from masculine influences. In this regard, traditional gender attributes provide one of the strongest arguments to explain risk-taking by males (Schmid-Mast et al., 2008). In the case of young people, research brings to light a sort of 'performative' value influenced by peer groups (AUTHOR et al., 2013). This enables certain risk practices to be understood as performative acts of masculinity. Therefore, risky social practices should be treated as an aspect of gender identity with a strong relational component, rather than simply being analyzed as individual traits (Scott-Samuel, 2009).

Research shows that signs of resistance, hardness and emotional control have profound implications for young adolescent males' health. Indeed, we can interpret their influences over certain dimensions of daily life - such as enthusiasm for sports - as key areas in which to analyze social interactions, because they produce and reinforce harmful symbolic codes associated with masculinity. Furthermore, psychological well-being related to body image is also linked to one's degree of conformity with traditional male ideology (Martin \& Govender, 2011). An important related issue is eating disorders among adolescent and young adult males, a topic largely underrepresented in the reviewed literature (Limbers et al., 2018). The literature also shows that when men are interested in improving their body image, they tend to focus on muscular development, which is widely deemed a sign of power and strength that is closely associated with seduction and sexual agency (McCabe \& Ricciardelli, 2004). Dissatisfaction with this aspect of male subjectivity may lead to practices that are very harmful to health, such as extreme diets, regular consumption of protein supplements and even of anabolic steroids (Kimergård, 2015). Thus, for example, description of the male body as a tool for action and power representation contributes to a belief 
that physical strength and aggressiveness are key components of masculinity's essence. This also implies the importance of questioning attitudes linked to the idea of supremacy, which legitimizes violence as a resource to maintain the gender order, which should be considered a health problem in itself. Similarly, sports and physical activities represent a key field in the analysis of social interactions involved in the production and reinforcement of values associated with the hegemonic idea of masculinity, such as attitudes of hardness or emotional control.

\section{Reaffirming versus challenging heteronormativity codes}

The studies reviewed highlight the consumption of recreational substances especially alcohol - as a key means of validating hegemonic/traditional masculinity. In general, males are less abstemious; they tend to be greater 'big drinkers' and cause more problems as a result of these intensive consumption patterns (de Visser \& Smith, 2007; Dempster, 2011; Hartley et al., 2014). However, a new impetus has emerged that transcends traditional binary gender approaches and instead focuses more on the diversity of masculinities associated with various styles of consumption (Mullen et al., 2007). The findings illustrate an inverse functionality of alcohol in the construction of gender identities. Increased consumption of recreational substances by younger girls is introducing changes in social interactions (Lyons \& Willott, 2008), thereby challenging existing notions of masculinity and femininity (Månsson, 2014). When considering a contemporary model of femininity characterized by experimenting with the consumption of psychoactive substances, traditionally associated with males, it is possible to derive a whole set of elements of gender conflict that both reaffirm and redefine hegemonic ideals of masculinity. Thus, some young people interpret 
these changes as the perpetuation of values, norms and beliefs surrounding a particular gender identity, while others deem them a basis for transgression (Deutsch, 2007). This is not only the case of girls adopting 'masculinized' patterns of consumption, but also of boys who demonstrate changing views regarding behaviours such as drunkenness and who refuse to define their masculinity around risk-taking.

This line of research highlights the 'experience of masculinity' as a social phenomenon that is intimately linked to sexuality (Richardson, 2010). Although masculinity should be defined in relation to sexuality from various perspectives (for example, a heteronormative point of view), it is primarily perceived in terms of greater interest in sporadic sexual relationships or a lack of need for emotional involvement (Marston \& King, 2006). Thus, behaviours such as sexual promiscuity have been mainly attributed to biological predisposition and unprotected intercourse has become an expression of manhood (Phillips, 2006). These ideas are key aspects to consider when formulating health promotion interventions, for instance regarding the importance of compliance with expectations in relation to condom use. Certainly, the reviewed literature reveals that men and women with less desire or need for emotional intimacy are more likely to eventually impose their views in the negotiation processes (Tschann et al., 2002). This means that in an analysis of risks, just like that of sexually transmitted diseases, one should consider the type of emotional relationship that men have with their sexual partners, among other factors.

\section{Threats to health and well-being for middle-aged men}

Gender differences and inequalities in health are embodied in adulthood, with studies mainly pointing to the social dynamics established between paid work and family life. 
Indeed, at the core of traditional constructions of masculinity lies the position of men as the main breadwinner in the family. This role conditions their involvement in the reproductive field, engendering differentiated exposures to risks. Similarly, in terms of paid work participation, significant gaps remain between men and women, whether related to hiring, remuneration or professional development.

\section{Interactions between productive and reproductive areas}

Labour participation is a key sphere in the construction of masculinities. It is particularly related to the idea of social status, mainly linked in the case of men to purchasing power. This frames a whole set of social expectations, priorities and practices.

On the other hand, the effects of the male breadwinner model's influences over men's involvement in reproductive work constitute an issue that is clearly linked to values and gender norms that define differentiated exposures to risks (Kanji \& Samuel, 2017). In so far as it contributes to the development of a notion of masculinity connected to the role of family protector, the decline of the male breadwinner model leads to a lack of identity among men as well as frustration associated with health outcomes. Although the literature on the subject is scarce and not very specific, psychological risks associated in particular with situations of financial stress caused by a loss or lack of employment have been identified. Thus, not only does unemployment have a greater negative impact on men's mental health (Artazcoz et al., 2004), but it has also been associated with impoverished lifestyles, influencing excess weight gains as well as other somatic risks, including increased risk of cardiovascular diseases (Lundin et al., 2014; Slebus et al., 2007). In the same way, Barrech et al. (2016) have shown that the negative effects of unstable working conditions in midlife are associated with low subjective well-being in retirement. In this sense, studies such as that conducted by 
Andersen et al. (2003) in Denmark reveal that in more egalitarian societies, these gender inequalities dissipate, as men and women in the same income stratus share almost the same prognostic factors.

The use of the gender approach as an analysis strategy in these studies is very limited and when it does appear, it exclusively focuses on models of traditional masculinity surrounding the earning of money, such as when men do not accept women's income in the family environment. This leads to situations such as early work incorporation, with health consequences when the labour market exposes men to poor working conditions that they nevertheless accept.

The need to juggle work responsibilities with taking care of a family and its impacts on health is central to understanding gender inequalities in health. Indeed, it provides evidence that some ill-health processes in males and females are intrinsically interwoven, hence the way in which relationships develop between them reflect limitations and opportunities for both (Kuhlmann \& Annandale, 2012). Men’s minor role in the informal care system represents one of the major debates over social welfare policy. Following this subject and its research lines bring us to a broader discussion: the benefits and health problems produced by work and family life compatibility (Backhans et al., 2007). Men's inferior involvement in the reproductive sphere of family life is related to the fact that their socialization has provided them with less knowledge and skills to care for the health of others. Moreover, in connection with the ideal of physical and emotional strength, this is both directly and indirectly linked to the fact that men access primary care health services less than women and are less involved in preventive initiatives (Noone \& Stepherns, 2008; White et al., 2018).

All of this additionally underlines the importance of implementing policies that are capable of generating positive changes in gender relations. This should be reflected 
in the greater application of the gender perspective in actions to involve men in health equity programmes. For example, from a relational perspective, another relevant topic pertains to the implications of these situations for parental involvement (Dolan \& Coe, 2011). Research has focused on health effects and one's well-being during the transition to parenthood. In heterosexual couples, for example, men and women are affected differently by this transition and we must consider the fact that one of the keys to successful parenthood adaptation is linked to both partners' efforts in this regard (Keizer et al., 2010). Accordingly, an important issue is to identify target groups among fathers who are in need of parental work leave, as this may be of benefit to the health of mothers, children and the fathers themselves (Mansdotter et al., 2010). In this regard, a noteworthy period to promote health intervention is during pregnancy and early parenthood; unsurprisingly, parents' prioritization of their own health is often low during this time, while the risks to their children's health appear to constitute the primary driving force for a lifestyle change. A more gender-transformative health promotion intervention amongst parents might increase men's involvement in this lifestyle change (Edvardsson et al., 2011). These changes bear implications for the health of men and women, which should be explored in greater depth through recognizing gender diversity and its intersections with other social inequality axes (Hankivsky, 2012).

\section{Adverse life experiences and health-illness coping strategies}

Gender dynamics not only condition participation within the reproductive context, but are also related to an element of social nature that seems to condition how people negotiate specific circumstances. In this sense, for example, important aspects in men's health that may have consequences in more advanced ages are the death of a child or spousal bereavement (Cohen-Mansfield et al., 2013) as well 
as the possible impact on health of being a childless man. These issues are connected with the development capacity of support networks (Klaus \& Schnettler, 2016).

Relating gender with differential exposure to risk additionally implies connecting coping with health-disease processes with the socialization of lifestyles. A central aspect is consideration of the 'world of excesses' (AUTHOR et al., 2012). This can be seen in a consideration that is widely described in the literature: men, to a greater extent than women, tend to channel their problems and frustrations through drug use and avoid asking for help, hence situations of frustration and/or isolation are more likely to emerge, often due to a lack of treatment of depressive states (Oliffe et al., 2012). Sometimes, this also results in the adoption of more radical measures, including violence against others (as in the case of gender-based violence) or against themselves (self-injury and suicide). These aspects are connected to a perception of control and resistance (stoicism) and thus form part of the hegemonic imaginary of masculinity described in the literature (Scott-Samuel, 2009). Therefore, the way in which the meanings of masculinity are assumed is at the basis of the differences that men establish in relation to their gender identity, conditioning their relationships with themselves and with others (Courtenay, 2000).

Consequently, the gender codes that are constructed based on behaviours and values that men and women perceive as part of the culture in society, influence in many ways how health-illness situations are negotiated. The literature indicates that men, more often than women, tend to cope with their problems by taking refuge in addiction or avoiding medical treatment (White et al., 2011b). As a result, symptoms of depression in men often remain undiagnosed (Emslie et al., 
2006). Among other health implications, the failure to recognize mental health problems may contribute to much higher suicide rates among men (Oliffe et al., 2012). Besides the fact that men often avoid asking for help or deny their state of discomfort, this being considered a symptom of weakness and vulnerability, other aspects related to disorders such as depression also come into play. Indeed, the criteria used to diagnose depression are often polarized around the signs of a traditionally perceived 'feminine' disease. These include the expression of sadness rather than anger, emotional numbness, substance abuse or impoverished interpersonal relationships, which are often more common symptoms in men's depression (Oliffe \& Phillips, 2008). Analyzing this issue from an intersectional perspective would allow us to delve into how men understand, represent and respond to critical events according to their living conditions as well as how this influences the 'opportunity structures' of the men themselves, while simultaneously conditioning those of other people.

\section{Men's health in old age}

The gender approach should help make visible how the intersection of productive and reproductive spheres usually places men in a position of advantage in accessing and controlling both material and non-material resources, along with health implications in the function of the social dynamics around which identities are 'negotiated'. In this way, the analysis should increase an understanding of masculinities by exploring how hegemonic conceptions change over time.

\section{Life cycle transitions and risks of loneliness}

Studies that focus on key vital events such as the transition to retirement remain scarce. Moreover, analyses strictly focusing on the age criterion may not fully capture the dynamics that are generated around these processes (Lohan, 2007). The incorporation of 
the life course approach should provide deeper insights into the cumulative effects of context in relation to significant events. Thus, for example, unwanted loneliness has a significant effect on health and quality of life in old age. It is related to factors such as reduced activity levels, physical and mental health problems and increased mortality rates (Luo et al., 2012). Recent literature has put the spotlight on the possible discordance between loneliness and social isolation among older adults (McHugh et al. 2017). Thus, when designing more effective health programmes, research has also emphasized the importance of distinguishing between social and emotional dimensions of loneliness (Dahlberg \& McKee, 2014). Becoming alone in old age can represent a decisive life event that brings about major changes, the results of which are contingent on causes, such as health status, financial resources, family situation and available welfare services. Emilsson and Stahl (2016) have explored the impacts of transitioning from a two-person to a single-person household on the everyday lives of elderly people, with men and women alike attempting to live as they always had, utilizing the same personal life strategies. However, men were better able to live as before on their own financial resources, whereas women were more likely to require the help of children, grandchildren and the welfare system.

On the other hand, literature has shown an increased risk of anxiety and mood disorders among men having lost their partner (Onrust \& Cuijpers, 2006) and in the same line, the risk of morbidity among widowed men may be greater, specifically for those remaining alone after the loss of a wife. Hauksdóttir et al. (2013) have demonstrated that widowers who remained single for four to five years after the loss of their wife reported greater susceptibility to anxiety, depression, difficulty falling asleep, a less meaningful life and other manifestations of psychological morbidity. Becoming a widower has also been related to an increased risk of death, highlighting that greater 
morbidity owing to lifestyle risk factors must not be excluded as an explanation for the mortality rates observed among widowers (Skulason et al., 2012). One way forward in this sense could be to deepen analysis of how diverse (or non-hegemonic/traditional) identity constructions imply a reinterpretation of norms with an impact on health and how these health/illness processes are negotiated in ways that differ from what would be expected within a binary and heteronormative vision. In this way, it would be interesting to identify the strategies that men who experience non-normative identities when they face these loneliness situations by trying to preserve their well-being. These strategies may serve as tools to design more specific health promotion programmes from a gender perspective.

\section{Retirement related to ill-health}

During adulthood, men may manifest singular aspects in the representation of their masculinities. As noted, the gender division of labour is at the root of some of the most important effects of the gender/health binomial. In this sense, scientific research points to some areas of study of considerable interest, such as the gendered interaction between mental health and unemployment.

Retirement has numerous effects on people, including the potential risk of obesity and/or alcohol consumption, especially among men (Halonen et al., 2017). However, we must look at the factor of labour market position. Overall, illnesses and conditions such as depression, strokes, diabetes, chronic lung disease and musculoskeletal disease are more common among those without paid employment due to early retirement (Alavinia \& Burdorf, 2008). Moreover, research highlights the fact that post-retirement, well-being is greatly affected by the advantages and disadvantages accumulated during the course of a person's life, with both labour market exit routes and post-retirement well-being understood as possible outcomes (Hallored et al., 2013). 
This means that the cumulative disadvantages of non-employment and non-standard work affect the careers and the subjective well-being of the elderly, with major negative effects emerging for men in old age (Ponomarenko, 2016). However, the heterogeneity of transitions to retirement must be taken into account, not only in terms of the timing of retirement, but also regarding the individual's capacity to endorse different roles. In the case of men, satisfaction with leisure activities upon retirement clearly increases the level of their well-being (Ryser \& Wernli, 2017). This is a subjet of considerable interest, but one that must be advanced from a gender perspective in the analysis of masculinities in response to their affective-sexual and gender identity diversity in relation to other inequality axes, such as social class.

Another important issue is that retirement provides an opportunity for increased civic engagement in regard to health promotion strategies. Overall, it has been found that workers from higher status occupations tend to volunteer more following retirement than do workers from lower status occupations. Similarly, van den Bogaard et al. (2014) have noted that while education does seem to directly boost volunteering, educational level does not appear to moderate retirement effects. Some literature has also analyzed the relationship between cognitive performance and social participation. For instance, Engelhardt et al. (2010) have indicated that all kinds of social involvement (employment, educational courses, voluntary or charity work, helping relatives or neighbours, sports, etc.) increase cognitive functions for both men and women. Accordingly, research shows social benefits for things such as the experience of companionship or the feeling of making an important contribution to society (Goth \& Smaland, 2014). Although there is widespread agreement regarding the importance of community activity for well-being, organizations may find it difficult to engage older men in generic non-gender-specific social activities (Milligan et al., 2015). In this sense, 
we must bear in mind that although community environments support some forms of the reproduction of inequalities, they also represent the basis for the transformation of gender-based demands.

Concerning long-term survival, the findings reported by Brockmann et al. (2009) show that early retirement may reflect both protective and selective processes in relation to mortality. Although healthy retirees may be protected during retirement, those with poor health (and as a result with less chance of survival) are more often filtered out of the labour market. For the former, early retirement is an asset, whereas for the latter, it is a necessity. The association between low socioeconomic position and disability retirement is also well established. However, the literature suggests that efforts to delay and prevent disability retirement should mainly focus on the lifestyle and cognitive factors associated with education as well as on factors related to social class, such as working conditions and power resources (Lawless et al., 2015; Leinonen et al., 2012). Moreover, Artazcoz et al. (2010) have noted that the relationship between early retirement and health status depends on the interaction between social class and gender. In fact, in all groups under study, early retirement on health-related grounds has been found to be related to poor health status, whereas forced early retirement for organizational reasons is associated with poor health status only among female manual workers. Therefore, future research should consider the specific type of work and additionally discuss its feminization or masculinization, alongside its relevance to the population being studied. It is also necessary that future studies include measuring instruments that are adapted to gender (i.e. to the gender-specific behaviours of the context of each country) rather than merely being divided by sex following a binary construction. 


\section{Implications for gendered health policy and future research}

The development of new meanings, values and social practices attributed to the idea of masculinity implies that policies should acknowledge the health differences and inequalities that exist among men. However, this would in turn limit the promotion of more positive forms of masculinity. To help counter this issue, we should evaluate and disseminate policies and examples of good practices aimed at promoting men's health in a way that contributes to the improvement of women's health, too. Our review shows that this is particularly necessary with regard to responsibilities within the domestic sphere, primarily based on men assuming responsibility for the informal care of dependent relatives or becoming more involved in the upbringing of their children (Scambor et al., 2014). In addition, we deem it necessary to develop and disseminate additional examples of how intersectionality and gender mainstreaming can be applied in a pragmatic way, addressing men with specific health needs as well. This is especially relevant for those who exhibit greater conformity with traditional ideals of masculinity as well as for men with non-normative masculinities. In any case, health promotion programmes and specific interventions should not be limited to addressing risk factors, but also to strengthening the approach taken when examining public health assets (AUTHOR et al., 2015).

Regarding gaps of knowledge and priorities for future research, after reviewing the available literature, we have found that the majority of analyses view ill-health as mere antagonistic processes between men and women. A gender-relational approach facilitates a better understanding of the lay knowledge and social practices of everyday life and would improve the design of health promotion and preventive actions. In the same vein, studies analyzing men's health in different socioeconomic groups remain very limited. In this sense, research should focus on the connections between gendered 
hegemonic social practices and institutionalized praxis, such as having to work long hours, do overtime or not having the right to paternity leave. Situations with health implications that might reinforce certain social roles between men and women, among other necessities, should be taken into account. This requires a more detailed analysis of the characteristics, living conditions and social circumstances of men who feel driven to perpetuate attitudes that resist manifestations of weakness/vulnerability through adopting practices that put their health at risk. However, at the same time, it is also necessary to analyze other ways of understanding masculinity and its identity traits that go beyond traditional hegemonic meanings. This includes masculinities related to affective-sexual diversity or non-binary gender identities. This should help bring to light more positive models of masculinity as well as demonstrate how non-hegemonic concepts influence health in men (and women).

\section{Limitations}

Our approach was a simplified analysis of identity. We summarized the emerging evidence using only two databases and restricted the search to papers published in English or Spanish; moreover, we mainly focused on European and Anglo-Saxon countries, where studies on men's health and masculinities are most developed. Furthermore, although we provided insights regarding the interaction of gender with other cross-cutting aspects of inequality and identified some needs within the literature in this regard, the paper has presented a limited intersectional perspective.

\section{Conclusion}

The studies reviewed indicate that the established dynamics between workplace and family contexts carry special significance. In the case of men, the workplace is a central focus point and constitutes the hegemonic representation of 
masculinity. Therefore, acknowledging men's gendered role as main family provider may not only condition participation in the reproductive context, but also play a vital role in gender-based norms that might lead to increased exposure to occupational health risks. For young men, the relationship between masculinity and health is primarily defined by behavioural explanations with an obvious performative component, such as imprudent driving or violent conduct, which are referred to in the literature as manly behaviours. This provides evidence that male hierarchies are associated with an idealized and/or dominant male image.

Different symbolic traits can be used to define masculinity in relation to body image, especially around sexuality and the use of recreational drugs. These areas are those where the most significant changes have been found in relation to identity codes, with clear implications for both male and female health.

We can conclude that ill-health processes are linked to forms of interaction between males and females as well as between men themselves. Thought and behavioural patterns are reflected in specific situations and circumstances, mediated by a gender-based order that carries limitations and risks as well as opportunities that affect health. Public health policies must initiate this change by recognizing that gender equity is fundamentally based on how human relationships are articulated.

\section{References}

Alavinia, S.M., \& Burdorf, A. (2008). Unemployment and retirement and ill-health: a cross-sectional analysis across European countries. International Archives of Occupational and Environmental Health, 82(1), 39-45.

Andersen, I., Osler, M., Petersen, L., Grønbæk, M., Prescott, E. (2003). Income and risk of ischaemic heart disease in men and women in a Nordic welfare country. International Journal of Epidemiology, 32, 367-374. 
Artazcoz, L., Benach, J., Borrell, C., \& Cortès, I. (2004). Unemployment and Mental Health: Understanding the Interactions Among Gender, Family Roles, and Social Class. American Journal of Public Health, 94(1), 82-88.

Artazcoz, L., Cortes, I., Borrell, C., Escriba-Aguir, V., \& Cascant, L. (2010). Gender and Social Class Differences Retirement and Health in Spain. Womens Health Issues, 20(6), 441-7.

Backhans, M.C., Lundberg, M., \& Månsdotter, A. (2007). Does increased gender equality lead to a convergence of health outcomes for men and women? A study of Swedish municipalities. Social Science \& Medicine, 64(9), 1892-1903.

Barrech, A., Baumert, J., Emeny, R.T., Gundel, H., \& Ladwig, K.H. (2016). Mid-life job insecurity associated with subjective well-being in old age: results from the population-based MONICA/KORA study. Scandinavian Journal of Work Environment \& Health, 42(2), 170-4.

Brockmann, H., Müller, R., \& Helmert, U. (2009). Time to retire - Time to die? A prospective cohort study of the effects of early retirement on long-term survival. Social Science \& Medicine, 69, 160-164.

Broom, D.H. (2009). Men's health and women's health-deadly enemies or strategic allies. Critical Public Health, 19(3-4), 269-277.

Cohen-Mansfield, J., Shmotkin, D., Malkinson, R., Bartur, L., \& Hazan, H. (2013). Parental Bereavement Increases Mortality in Older Persons. Psychological Trauma, 5(1), 84-92.

Connell, R.W. (2012). Gender, health and theory: conceptualizing the issue, in local and world perspective. Social Science \& Medicine, 74, 1675-1683.

Connell RW. Gender and Power: Society, the Person and Sexual Politics. Standford CA: Standford University Press; 1987. 
Courtenay, W.H. (2003). Key determinants of the health and the well-being of men and boys. International Journal of Men's Health, 2(1), 1-30.

Courtenay, W.H. (2000). Constructions of masculinity and their influence on men's well-being: a theory of gender and health. Social Science \& Medicine, 50(10), 1385-1401.

Dahlberg, L., \& McKee, K.J. (2014). Correlates of social and emotional loneliness in older people: evidence from an English community study. Aging \& Mental Health, 18(4), 504-14.

de Visser, R.O. (2009). I'm not a very manly man. Qualitative insights into young men's masculine subjectivity. Men and Masculinities, 11(3), 367-71.

de Visser, R.O., \& Smith, J. (2007). Alcohol Consumption and Masculine Identity among Men. Psychology and Health, 22, 595-614.

Dempster S. I. (2011). I drink, therefore I'm man: gender discourses, alcohol and the construction of British undergraduate masculinities. Gender \& Education, 23(5), $635-53$.

Deutsch, F.M. (2007). Undoing gender. Gender \& Society, 21(1), 106-127.

Dolan, A., \& Coe, C. (2011). Men, masculine identities and childbirth. Sociology of Health and Illness, 33, 1019-1034.

Edvardsson, K., Ivarsson, A., Eurenius, E., Garvare, R., Nyström, M.E., Small, R., \& Mogren, I. (2011). Giving offspring a healthy start: parents'experiences of health promotion and lifestyle change during pregnancy and early parenthood. BMC Public Health, 11:936. doi: 10.1186/1471-2458-11-936

Emilsson, U.M., Stahl, A. (2016). Good personal finances or a strong social capital on different life conditions of importance for an active life when becoming alone in old age. European Journal of Social Work, 19(5), 749-63. 
Emslie, C., Damien, R., Ziebland, S., \& Hunt, K. (2006). Men's accounts of depression: Reconstructing or resisting hegemonic masculinity? Social Science \& Medicine, $62,2246-2257$.

Engelhardt, H., Buber, I., Skirbekk, V., \& Prskawetz, A. (2010). Social involvement, behavioural risks and cognitive functioning among older people. Ageing \& Society, 30, 779-809.

Evans, J., Frank, B., Oliffe, J.L., Gregory, D. (2011). Health, Illness, Men and Masculinities (HIMM): a theoretical framework for understanding men and their health. Journal of Men's Health \& Gender, 8(1), 7-15.

Godard, M. (2016). Gaining weight through retirement? Results from the SHARE survey. Journal of Health Economics, 45, 27-46.

Goth, U.S., \& Smaland, E. (2014). The Role of Civic Engagement for Men's Health and Well Being in Norway-A Contribution to Public Health. International Journal of Environmental Research and Public Health, 11(6), 6375-87.

Graham, H. (2002). Building an Inter-disciplinary science of health inequalities: The example of life-course research. Social Science \& Medicine, 55(11), 2006-2016.

Hallerod, B., Orestig, J., \& Stattin, M. (2013). Leaving the labour market: the impact of exit routes from employment to retirement on health and wellbeing in old age. European Journal of Ageing, 10(1), 25-35.

Halonen, J.I., Stenholm, S., Pulakka, A., Kawachi, I., Aalto, V., Pentti, J., et al. (2017). Trajectories of risky drinking around the time of statutory retirement: a longitudinal latent class analysis. Addiction, 112(7), 1163-70.

Hankivsky, O. (2012). Women's health, men's health, and gender and health: Implications of intersectionality. Social Science \& Medicine, 74(11), 17121720. 
Hartley, J.E.K., Wight, D., \& Hunt, K. (2014). Presuming the influence of the media: teenagers' constructions of gender identity through sexual/romantic relationships and alcohol consumption. Sociology of Health \& Illness, 36(5), 772-86.

Hauksdottir, A., Valdimarsdottir, U., Furst, C.J., \& Steineck, G. (2013). Long-term mental health of men who lose a wife to cancer-a population-based follow-up. Psycho-Oncology, 22(2), 352-61.

Jefferson, T. (2002). Subordinating hegemonic masculinity. Theoretical Criminology, 6(1), 63-88.

Kanji, S., \& Samuel, R. (2017). Male Breadwinning Revisited: How Specialisation, Gender Role Attitudes and Work Characteristics Affect Overwork and Underwork in Europe. Sociology, 51(2), 339-356.

Kawachi, I., Subramanian, S.V., \& Almeida-Filho, N. (2002). A glossary for health inequalities. Journal of Epidemiology \& Community Health, 56(9), 647-652.

Keizer, R., Dykstra, P.A., Poortman, A.R. (2010). The Transition to Parenthood and Well-Being: The Impact of Partner Status and Work Hour Transitions. Journal of Family Psychology, 24(4), 429-438.

Kimergård, A. (2015). A qualitative study of anabolic steroid use amongst gym users in the United Kingdom: motives, beliefs and experiences. Journal of Substance Use, 20(4), 288-294.

Klaus, D., \& Schnettler S. (2016). Social networks and support for parents and childless adults in the second half of life: Convergence, divergence, or stability? Advances in Life Course Research, 29, 95-105.

Kuhlmann, E., \& Annandale, E. (2012). Mainstreaming gender into healthcare: a scoping exercise into policy transfer in England and Germany. Current Sociology, 60(4), 551-568. 
Lawless, M., Buggy, C.J., \& Codd, M.B. (2015). Educational influences on early retirement through disability in Ireland. Occupational Medicine-Oxford, 65(4), $303-8$

Leinonen, T., Martikainen, P., \& Lahelma, E. (2012). Interrelationships between education, occupational social class, and income as determinants of disability retirement. Scandinavian Journal of Public Health, 40(2), 157-66.

Limbers, C. A., Cohen, L. A., \& Gray, B. A. (2018). Eating disorders in adolescent and young adult males: prevalence, diagnosis, and treatment strategies. Adolescent Health, Medicine and Therapeutics, 9, 111-116.

Lorber, J. (1994). Paradoxes of Gender. New Haven, CT: Yale University Press.

Lundin, A., Falkstedt, D., Lundberg, I., \& Hemmingsson, T. (2014). Unemployment and coronary heart disease among middle-aged men in Sweden. Occupational and Environmental Medicine, 71(3), 183-8.

Luo, Y., Hawkley, L.C., Waite, L.J., \& Cacioppo, J.T. (2012). Loneliness, health, and mortality in old age: A national longitudinal study. Social Science \& Medicine, 74(6), 907-914.

Lyons, A.C., \& Willott, S.A. (2008). Alcohol Consumption, Gender Identities and Women's Changing Social Positions. Sex Roles, 59, 694-712.

Malmusi, D., Vives, A., Benach, J., \& Borrell, C. (2014). Gender inequalities in health: exploring the contribution of living conditions in the intersection of social class. Global Health Action, 7. http://dx.doi.org/10.3402/gha.v7.23189

Mansdotter, A., Fredlund, P., Hallqvist, J., Magnusson, C. (2010). Who takes paternity leave? A cohort study on prior social and health characteristics among fathers in Stockholm. Journal of Public Health Policy, 31(3), 324-41. 
Månsson, E. (2014). Drinking as a Feminine Practice: Post-Feminist images of women's drinking in Swedish women's magazines. Feminist Media Studies, 14(1), 56-72.

Marston, C., \& King, E. (2006). Factors that shape young people's sexual behaviour: a systematic review. The Lancet, 368: 1581-1586.

Martin, J., \& Govender, K. (2011). "Making muscle junkies": Investigating traditional masculine ideology, body image discrepancy, and the pursuit of muscularity in adolescent males. International Journal of Men's Health, 10(3), 220-239.

McCabe, M.P., \& Ricciardelli, L.A. (2004). Body image dissatisfaction among males across the lifespan: a review of past literature. Journal of Psychosomatic Research, 56, 675-685.

McHugh, JE, Kenny, RA, Lawlor, BA, Steptoe, A, \& Kee, F. (2017). The discrepancy between social isolation and loneliness as a clinically meaningful metric: findings from the Irish and English longitudinal studies of ageing (TILDA and ELSA). Int J Geriatr Psychiatry, 32(6), 664-674.

Milligan, C., Payne, S., Bingley, A., \& Cockshott, Z. (2015). Place and wellbeing: shedding light on activity interventions for older men. Ageing \& Society, 35(1), 124-49.

Mullen, K., Watson, J., Swift, J., \& Black, D. (2007). Young men, masculinity and alcohol. Drugs: Education, Prevention, and Policy, 14(2): 151-165.

Noone, J.H., \& Stepherns, C. (2008). Men, masculine identities and health care utilisation. Sociology of Health \&Illness, 30(5), 711-25.

OECD/ ITF. (2018). Road Safety Annual Report 2018. OECD Publishing.

Oliffe, J.L., \& Phillips, M.J. (2008). Men, depression and masculinities: A review and recommendations. Journal of Men's Health, 5(3), 194-202. 
Oliffe, J.L., Ogrodniczuk, J.S., Bottorff, J.L., Johnson, J.L., \& Hoyak, K. (2012). "You feel like you can't live anymore": suicide from the perspectives of Canadian men who experience depression. Social Science \& Medicine, 74(4), 506-14.

Onrust, S.A., \& Cuijpers, P. (2006). Mood and anxiety disorders in widowhood: a systematic review. Aging \& Mental Health, 10, 327-334

Perry, D.G., \& Pauletti, R.E. (2011). Gender and Adolescent Development. Journal of Research on Adolescence, 21(1), 61-74.

Phillips, D.A. (2006). Masculinity, male development, gender, and identity: Modern and postmodern meanings. Issues in Mental Health Nursing, 27, 403-23.

Phillips, S.P. (2011). Including Gender in Public Health Research. Public Health Reports, 126(Suppl 3), 16-21.

Pilcher, J. \& Whelehan, I. (2004). Fifty key concepts in gender studies. London: SAGE Publications.

Ponomarenko, V. (2016). Cumulative disadvantages of non-employment and nonstandard work for career patterns and subjective well-being in retirement. Advances in Life Course Research, 30, 133-48.

Richardson, D. (2010). Youth masculinities: compelling male Heterosexuality. British Journal of Sociology, 61(4), 737-56.

Robertson, L.M., Douglas, F., Ludbrook, A., Reid, G., \& van Teijlingen, E. (2008). What works with men? A systematic review of health promoting interventions targeting men. BMC Health Services Research, 8, 141. doi: 10.1186/1472-69638-141.

Ryser, V.A., \& Wernli, B. (2017). How does transitioning into retirement impact the individual emotional system? Evidence from the Swiss context. Advances in Life Course Research, 32, 42-54. 
Sabo D. The study of masculinities and men's health: An overview. En: Kimmel EM, Hearn J, Connell RW, (ed.). Handbook of studies on men and masculinities. Thousand Oaks, CA: Sage; 2005. p. 326-353

Scambor, E., Bergmann, N., Wojnicka, K., Belghiti-Mahut, S., Hearn, J., Holter, Ø.,... White, A. (2014). Men and Gender Equality: European Insights. Men and Masculinities, 17(5), 552 - 577.

Schmid-Mast, M., Sieverding, M., Esslen, M., Graber, K., \& Jäncke, L. (2008). Masculinity causes speeding in young men. Accident Analysis and Prevention, 40, 840-842.

Schofield, T., Connell, R.W., Walker, L., Wood, J., Butland, D. (2000). Understanding men's health: A gender relations approach to masculinity health and illness. Journal of American College of Health, 48(6), 247-56.

Scott-Samuel, A. (2009). Patriarchy, masculinities and health inequalities. Gaceta Sanitaria, 23(2), 159-160.

Sen, G., \& Östlin, P. (2007). Unequal, unfair, ineffective and inefficient. Gender inequity in health: Why it exists and how we can change it. Geneva: WHO.

Slebus, F.G., Kuijer, P.P.F.M., Willems, J.H.B.M., Sluiter, J.K., Frings-Dresen, M.H.W. (2007). Prognostic factors for work ability in sicklisted employees with chronic diseases. Occupational and Environmental Medicine, 64, 814-819.

Smith, J.A., White, A.K., Richardson, N., Robertson, S., \& Ward, M. (2009). The men's health policy contexts in Australia, the UK and Ireland: advancement or abandonment? Critical Public Health, 19(3-4), 427-440.

Solar O, Irwin A, Vega J. Determinants of health disease: overview and framework. En: Detels R, Beaglehole R, Lansang MA, Gulliford M, (ed.). Textbook of Public Health. Oxford: Oxford University Press; 2009. p. 101-119. 
Skulason, B., Jonsdottir, L.S., Sigurdardottir, V., \& Helgason, AR. (2012). Assessing survival in widowers, and controls - A nationwide, six- to nine-year follow-up. BMC Public Health, 12, 96. doi: 10.1186/1471-2458-12-96

Tschann, J.M., Adler, N.E., Millstein, S.G., Gurvey, J.E., \& Ellen, J.M. (2002). Relative power between sexual partners and condom use among adolescents. Journal of Adolescent Health, 31(1), 17-25.

Van den Bogaard, L., Henkens, K., \& Kalmijn, M. (2014). Pasts that last: The moderating role of education and former occupation for men's volunteering after retirement. Research in Social Stratification and Mobility, 36, 87-100.

Wedgwood, N. (2009). Connell's theory of masculinity - its origins and influences on the study of gender1. Journal of Gender Studies, 18, 329-339.

White, A., Seims, A., Cameron, I., \& Taylor, T. (2018). Social determinants of male health: a case study of Leeds, UK. BMC Public Health, 18, 160. doi: 10.1186/s12889-018-5076-7.

White, A., McKee, M., Richardson, N., de Visser, R.O., Madsen, S.A., de Sousa, B., Hogston, R., Zatonski, W., \& Makara, P. (2011a). Europe's men need their own health strategy. British Medical Journal, 343, d7397. doi:

10.1136/bmj.d7397White, A., de Sousa, B., de Visser, R.O., Hogston, R., Madsen, S.A., Makara, P.,... Zatonski, W. (2011b). The State of Men's Health in Europe. Brussels: European Commission.

World Health Organization (2018). Strategy on the health and well-being of men in the WHO European Region. Copenhagen: WHO Regional Office for Europe. 